\title{
The Vulnverability Cube: A Multi-Dimensional Framework for Assessing Relative Vulnerability
}

\author{
Brenda B. Lin · Philip E. Morefield
}

Received: 30 September 2010/Accepted: 25 April 2011/Published online: 3 June 2011

(C) The Author(s) 2011. This article is published with open access at Springerlink.com

\begin{abstract}
The diversity and abundance of information available for vulnerability assessments can present a challenge to decision-makers. Here we propose a framework to aggregate and present socioeconomic and environmental data in a visual vulnerability assessment that will help prioritize management options for communities vulnerable to environmental change. Socioeconomic and environmental data are aggregated into distinct categorical indices across three dimensions and arranged in a cube, so that individual communities can be plotted in a three-dimensional space to assess the type and relative magnitude of the communities' vulnerabilities based on their position in the cube. We present an example assessment using a subset of the USEPA National Estuary Program (NEP) estuaries: coastal communities vulnerable to the effects of environmental change on ecosystem health and water quality. Using three categorical indices created from a pool of publicly available data (socioeconomic index, land use index, estuary condition index), the estuaries were ranked based on their normalized averaged scores and then plotted along the three axes to form a vulnerability cube. The position of each community within the three-dimensional
\end{abstract}

B. B. Lin - P. E. Morefield

Office of Research and Development, U.S. Environmental Protection Agency (8601P), 1200 Pennsylvania Avenue, NW Washington, DC 20460, USA

B. B. Lin

AAAS Science and Technology Policy Fellowship, AAAS, 1200 New York Avenue, Washington, DC 20005, USA

B. B. Lin $(\varangle)$

CSIRO Marine and Atmospheric Research, Climate Adaptation Flagship, 107-121 Station Street, Private Bag 1, Aspendale, VIC 3095, Australia

e-mail: bbclin@gmail.com; brenda.lin@csiro.au space communicates both the types of vulnerability endemic to each estuary and allows for the clustering of estuaries with like-vulnerabilities to be classified into typologies. The typologies highlight specific vulnerability descriptions that may be helpful in creating specific management strategies. The data used to create the categorical indices are flexible depending on the goals of the decision makers, as different data should be chosen based on availability or importance to the system. Therefore, the analysis can be tailored to specific types of communities, allowing a data rich process to inform decision-making.

Keywords Decision assessment - Vulnerability ·

National Estuary Program - Socioeconomic · Land use . Estuary condition $\cdot$ Typologies

\section{Introduction}

An emergent problem for decision-makers is the diversity and abundance of information available for vulnerability assessments. Research on knowledge management across disciplines has found that the quality of decisions correlates positively with the amount of information up to a certain point, after which further information is no longer integrated into the decision-making process (Eppler and Mengis 2004). Excess information can impede the identification of relevant information because decision-makers ignore any information that exceeds their information processing capacity (Hwang and Lin 1999; Bawden 2001). Such information processing limits are part of the challenges associated with vulnerability assessments related to environmental change (e.g., climate change, land use change), as assessments of this type in essence must be multidimensional (Cutter and Finch 2008). Such complexity may 
impede management decisions to protect socio-ecological systems from a changing environment.

Vulnerability has been used and defined in a number of ways depending on the complexity of the system and the context of the problem. In this paper, we use the Intergovernmental Panel on Climate Change's (IPCC) definition of vulnerability as "the degree to which a system is susceptible to, or unable to cope with, adverse effects of climate change, including climate variability and extremes. Vulnerability is a function of the character, magnitude, and rate of climate variation to which a system is exposed, its sensitivity, and its adaptive capacity" (IPCC 2007). Although this definition is focused on climate related stressors, it can be applied to global environmental change writ large and to any endeavor that contemplates the potential for adaptation to diminish the costs of a future environmental change (Yohe and Tol 2002). Vulnerability depends critically on context, as social and ecological vulnerability are determined by a complex range of factors, and the reference to sensitivity and adaptive capacity in this definition point to the need to consider these factors in an integrated and inter-related fashion with vulnerability (Gallopín 2006).

Although there are numerous approaches to studying vulnerability in socio-ecological systems, an emerging consensus within the global environmental change community is to bring information and concepts from various disciplines together within assessments in order to address the full complexity of vulnerability (Eakin and Luers 2006). The ability to hybridize conceptual frameworks of knowledge from the diverse disciplines into one singular assessment will create greater relevancy and utility of the assessment for decision-makers (Eakin and Luers 2006). In order to incorporate this broad range of information into assessments, it is necessary to develop frameworks and methodologies that facilitate the processing and integration of diverse data into single assessments. Additionally, the challenge to present information in an easily understood manner (Simpson and Prusak 1995) where data are compressed, aggregated, and easily visualized is significant (Ackoff 1967; Meyer 1998).

In this paper, we advance a conceptual framework proposed by Fraser (2007) and present a methodology for vulnerability assessment that seeks to take on the above challenges without compromising the depth of information being provided. At the same time we recognize, as others have, the practical and heuristic advantages of framing complex socio-ecological issues in a way that is inherently multi-dimensional (Cutter and Finch 2008; Eakin and Luers 2006; Brooks and others 2005). Here, we present the vulnerability cube, a visualization approach that integrates a variety of socioeconomic and environmental variables into a unified assessment and reflects the multi-dimensional, interdisciplinary nature of vulnerability as well as the sensitivity and adaptive capacity of a community to environmental change.

\section{The Vulnerability Cube}

The vulnerability cube is an assessment methodology for organizing and analyzing multiple datasets and can be used across a variety of subjects (e.g., ecosystems, communities) and spatial scales. The steps toward structuring information in order to produce a vulnerability cube are to

(1) document the range of available datasets from a variety of scales and a diversity of disciplines,

(2) select metrics from the datasets based on utility and appropriateness of each metric,

(3) collapse the metrics into categorical indices, and

(4) plot and present the data in a 3-dimensional cube in order to visualize the relative vulnerability of subjects against one another.

We have chosen to limit the analysis to three indices because it has been shown that decision quality increases when information is limited to fewer dimensions (Hwang and Lin 1999), and the visual display of information is often limited to three dimensions. Three dimensional cube displays of information have been employed in a number of fields as a communication tool in order to elucidate the relationship between categories of influence. Fraser (2007) uses a cube framework to identify vulnerability to climate change in food systems focusing on changes in the agroecosystem, livelihood, and institutional capacity. Fraser uses the cube to compare regions and looks at trends over time by studying the paths of different regions through the cube space. In education communication studies, visual cubes have been used to compare the richness, interactivity, and accessibility of various types of electronic media (e.g., text, simulations, online discussions) for active learning (Repenning and others 1998). In knowledge management studies, they have been used to show how barriers in knowledge dissemination occur differently at the individual and organization scales for providers and consumers (Luggar and Kraus 2001), and in innovation studies, they have been used to show how different aspects of organization structure can stifle innovation (Glor 2001). Parkes and others (2010), in a study of watershed governance, also use a three-dimensional visual device to illustrate the multifaceted and multi-dimensional nature of environmental management problems and solutions.

In the vulnerability cube each index represents not only a unique dimension of the cube, but also a unique dimension of vulnerability. One corner of the cube necessarily represents the combination of characteristics which exhibit 
higher vulnerability while the opposite corner necessarily represents characteristics of lower vulnerability (Fig. 1a). This type of visualization allows subjects (e.g., communities, ecosystems, watersheds, etc.) to be compared with the conclusion that those located closer to the high vulnerability node are more vulnerable to environmental change in relation to communities that are located closer to the low vulnerability node.

The vulnerability cube can be used in various ways to better understand vulnerability and to help develop adaptation options. Subjects located within the same region of the cube can be grouped into typologies (i.e., "sub-cubes"; Fig. 1b) to identify subjects that exhibit similar vulnerability characteristics. An example of a community typology may be large, urban communities exhibiting water quality problems from increasing impervious surface coverage or small, urban communities experiencing water quality problems due to agricultural pollution. The two communities exhibit different vulnerability characteristics and will likely adopt very different adaptation strategies. The use of typologies will allow practitioners to understand the category of vulnerability (e.g., environmental, economic) that communities are challenged by as well as discern the direction in which the community must move in order to reduce the level of vulnerability currently exhibited (Fig. 1c).

Developing a system that allows for the integration of diverse data as well as aggregates and clearly presents multi-dimensional data will improve the ability to identify key vulnerabilities and to prioritize adaptation options that reduce vulnerability to environmental change within communities. The ability to identify typologies of communities allows for the development of specific typology based strategies and the transfer of adaptation strategies between communities within a typology. Different adaptation strategies should be developed for each typology, as communities should continually be striving to move themselves in the direction of the low vulnerability node via the three axes of the vulnerability cube (Fig. 1c). Subsequent assessments of the communities using the cube analysis can be undertaken to monitor and evaluate if the communities are moving toward a lower vulnerability position.

Research regarding adaptation decision-making indicates that decisions to adopt and modify measures and practices are rarely made relative to one risk alone, rather in light of a mix of conditions and risks; and decisions to adopt or modify management or practices are usually not made in a 'once-off' manner, but in a dynamic, on-going 'trial-and-error' process (Smit and Skinner 2002). Therefore, the ability to integrate multi-dimensional data that represents a mix of conditions and risks simultaneously gives practitioners a well-rounded set of information on
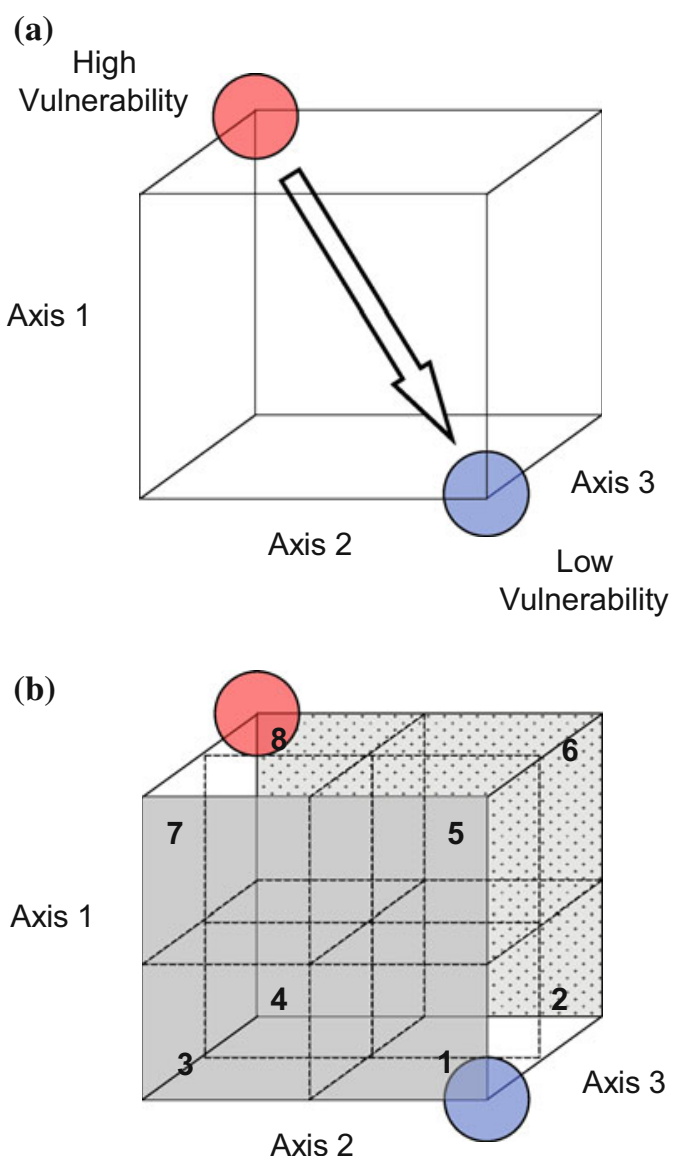

(c)

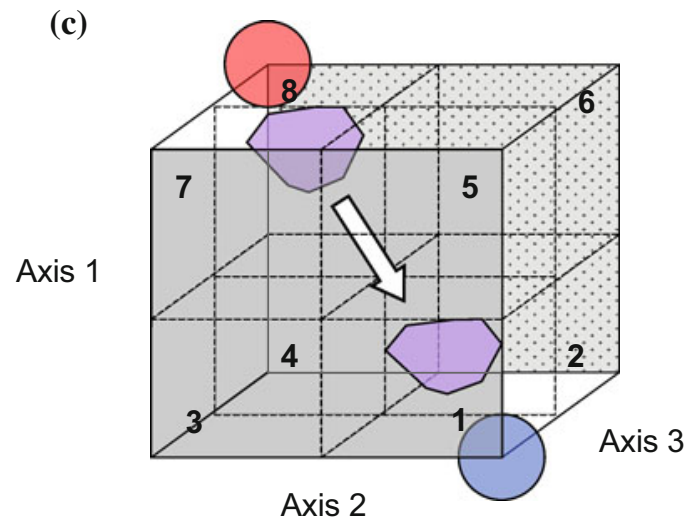

Fig. 1 The vulnerability cube is a system of compiling and collapsing data into three axes in 3D format, with one node representing an area of high vulnerability, and the opposite node representing an area of low vulnerability (a). The goal is to plot communities within the cube using the collapsed data in order to understand their level of vulnerability judged by their position relative to the low vulnerability node. The cube can be split into eight subcubes as a way to cluster communities with similar vulnerabilities into typologies (b). The goal is to move communities toward a lower vulnerability position (c)

which to base decisions. Changes in population patterns and land use development also affect vulnerability in space and time and require a multidimensional construct to fully 
understand these changes (Cutter and Finch 2008). In this way, the cube can be an effective tool to monitor vulnerability through time and evaluate the efficacy of specific practices to reduce vulnerability.

We believe that this methodology presents an improvement in vulnerability assessments to decisionmakers because it allows for specific types and relative magnitudes of different vulnerabilities to be elucidated as an outcome of the assessment. Many previous assessments have created single summary scores that allowed them to delineate groupings of communities into least to most vulnerable categories, but were unable to distinguish specific areas of vulnerability (e.g., Cutter and others 2003; Brooks and others 2005). For example, in one study, communities placed in the same category of "most vulnerable" had similar scores, but their vulnerability was caused by very different factors (Cutter and others 2003). The vulnerability of one community was largely based on the density of the built environment; another community was affected mainly by age, poverty, and race; and a third community was deemed most vulnerable because of its large debt to revenue ratio and its high reliance of employment in a single sector (Cutter and others 2003).

Conceptualizing three different dimensions of vulnerability as a cube can differentiate communities in a way that is intuitive, informative, and useful with respect to the identification of management goals and strategies. While we do not employ a rigorous application of statistical methods to create or validate metrics of vulnerability, we find that other assessments of vulnerability and risk utilize, to some degree, ad hoc aggregation or binning approaches similar to those used in this paper (Cutter and Finch 2008; Good and others 2008; Milman and Short 2008; Patrick and others 2009). While more thorough statistical treatments may be called for in many situations, here we focus on the utility of the cube as a conceptual framework, relying on intuitive, commonly used vulnerability metrics, and for now forego the trade-off of simplicity and interpretability for statistical rigor.

\section{An Example of the Vulnerability Cube Using the National Estuary Program}

As an example of this methodology, we have chosen to use communities in the USEPA's National Estuary Program (NEP), a set of 28 estuaries spread nationally across the coastal United States, to demonstrate how estuary communities (as the subjects) differ in type and level of vulnerability to environmental change (USEPA 2007). Estuaries are bodies of water that form the transition zone between fresh water (e.g., rivers) and saltwater (e.g., ocean), providing a unique environment for wildlife, fisheries, and a range of ecosystem services important to society (Beck and others 2001; Worm and others 2006). Coastal settlements and the historic human intervention of coastal areas has led to increasing stresses in these zones (Halpern and others 2008), requiring greater integration of socioeconomic and environmental management (Turner and others 1996). The impact of environmental change may further exacerbate current challenges of pollution and overuse by increasing the rate of sea level rise as well as altering rates of nutrient and sediment delivery into the system (Scavia and others 2002). Eutrophication and decreased water clarity will reduce estuary health and water quality, impacting fisheries and coastally based communities (Roessig and others 2004). Comparing vulnerability across estuaries can indentify leverage points for reducing vulnerability to environmental change, which is likely to manifest through increasing drivers of nutrient pollution through land use change and increasing climate impacts on coastal infrastructure. Identification of particularly vulnerable regions can serve as an entry point for both understanding and addressing the processes that cause and exacerbate vulnerability (Yohe and Tol 2002; Brooks and Adger 2003; O'Brien and others 2004).

The goals of the National Estuary Program are to promote comprehensive planning efforts to protect nationally significant estuaries in the US that are threatened by pollution, development, or overuse (USEPA 2007). The NEP estuaries are geographically distinct communities designated by the USEPA Office of Wetlands, Oceans, and Watersheds, and the program has sought to maintain a stake-holder driven, collaborative process to address estuary protection and restoration plans. The NEPs, therefore, provide an interesting system that is highly vulnerable to changes in future climate and land use and may be well served by adopting a multi-criteria vulnerability assessment tool that encourages visual communication of targeted vulnerability categories. Local managers already bring considerable insight into the specific challenges of managing for water quality within their estuaries; nevertheless, comparative assessments and consistent data can better support decision-making. Analysis of the estuaries will allow us to better understand how the vulnerability cube may enhance interpretation of relative vulnerability, and how it may inform adaptation and management strategies in estuaries dealing with the effects of environmental change on ecosystem health and water quality.

\section{Materials and Methods}

\section{Data Collection and Index Composition}

There are several challenges to data collection when choosing from the plethora of available metrics that will be 
collapsed into a single multi-metric index. A number of papers have examined the methodology of index creation for the purposes of assessing vulnerability at various scales (Kraay and others 1999; Yohe and Tol 2002; Brooks and others 2005; Birkmann 2007; Vincent 2007; Norton and others 2009). It has been noted that previous attempts to assess vulnerability have encountered similar data and conceptual problems in characterizing vulnerability, and that it is highly complex and difficult to quantify because many different factors can influence vulnerability (Yohe and Tol 2002). Because of this difficulty, we have tried to collect data that is representative of the metrics used in many other vulnerability and risk assessment studies. However, many of these studies were international in scope, and the metrics were frequently compiled at a national level. This study consists of community groups of a much smaller scale within a domestic setting, thereby requiring different sources and slightly different types of data.

We used a general guideline for data selection, taking into account a variety of factors regarding suitability, confidence, relevance, and scale of data that will be necessary to consider when creating the index.

1. What metrics exist for the systems or regions of interest?

2. Are the metrics consistent with regards to time period, collection protocols, spatial resolution, etc. across all systems or regions?

3. Does each metric provide relevant information?

4. Are any metrics redundant?

Such questions should be considered in the process of selecting individual metrics; however, the selection of metrics is generally flexible and can accommodate a wide variety of goals and community choices. Previous research examining multi-metric indices has shown that flexible approaches that allow user control in choice and number of indices and assigned weighting allow for the methodology to be applied broadly based on specific geographies and purposes (Norton and others 2009). Additionally, transparency in the process of creating multi-metric indices will reduce the level of uncertainty for end-uses of the indices and the analysis (Vincent 2007).

For this analysis estuary condition, land use, and socioeconomic indices were chosen because each index relates to an area of the urban ecosystem that can heavily impact long-term estuary health. All data used from the multi-metric indices were publically available and free of charge, ensuring open access to the metrics used within the analysis. Because of data limitations regarding equivalent land use data across space and time, the analyses were isolated to the 12 NEPs located in the Northeast Region (NE) and three NEPs located in the Gulf Coast Region (GC) for a total of 15 NEPs (Fig. 2).
Each of these indices was constructed as one axis of the vulnerability cube. The first set of data builds an index of current estuary condition as a reflection of the current level of estuary health. This index was included because current conditions of estuary health will determine the level of impact an estuary can absorb before reaching a threshold level of poor condition (USGCRP 2008). An estuary that already has poor condition will be more vulnerable to environmental change stressors than an estuary that is in good condition as the systems can deteriorate further, making it increasingly difficult to rehabilitate. Data formulating the estuary condition index were gathered from the National Estuary Program Coastal Condition Report (USEPA 2007) based on data collected as a part of USEPA's National Coastal Assessment. The data were collected once for each NEP from 1997 through 2003 and are the most comprehensive and nationally consistent data available related to estuarine condition. The data collected were used to create aggregate multi-metric scores of water quality, sediment quality, benthic health, and fish contaminants, and we created an index (estuary condition) using the average of the four pre-normalized scores (Table 1). The benthic health index is a region specific measure of the diversity and population size of indicator species and was developed as part of USEPA's National Coastal Assessment (NCA) (Engle and others 1994; Weisberg and others 1997; Engle and Summers 1999; Van Dolah and others 1999; Paul and others 2001; USEPA 2007). The fish tissue contaminant index was also a product of the NCA and was created by comparing fish tissue levels of 16 contaminants to USEPA risk-based thresholds (USEPA 2000, 2007). Metrics used by USEPA (2007) to create the water quality index were dissolved inorganic nitrogen, dissolved inorganic phosphorous, chlorophyll a, water clarity, and dissolved oxygen. Metrics for the sediment quality index were sediment toxicity, sediment contaminants, and total organic carbon.

The second set of data was used to build a land use index of each NEP to assess the vulnerability of the estuary based on present land use and land use changes observed between 1996 and 2006. The metrics used in this index have been identified as key indicators of vulnerability and resilience (Brenkert and Malone 2005; Norton and others 2009) and are frequently associated with increased run-off and pollution (Walling 2006; Halpern and others 2008). Also, the degree of ecosystem disturbance in estuaries has been shown to be inversely related to ecological resilience (Thrush and others 2008). The land use index was calculated using the Coastal Change Analysis Program (C-CAP) Regional Land Cover data from the National Oceanic and Atmospheric Administration (NOAA 2009). The C-CAP data represent a nationally standardized database of land cover and land use change information for the coastal 
Fig. 2 A map of the 15 NEP estuaries included in the analysis, distinguished by their locations in the Northeast and the Gulf Coast. A legend with the abbreviated code for each estuary has been included. This code is used within the manuscript and typology cube figure (Fig. 4)
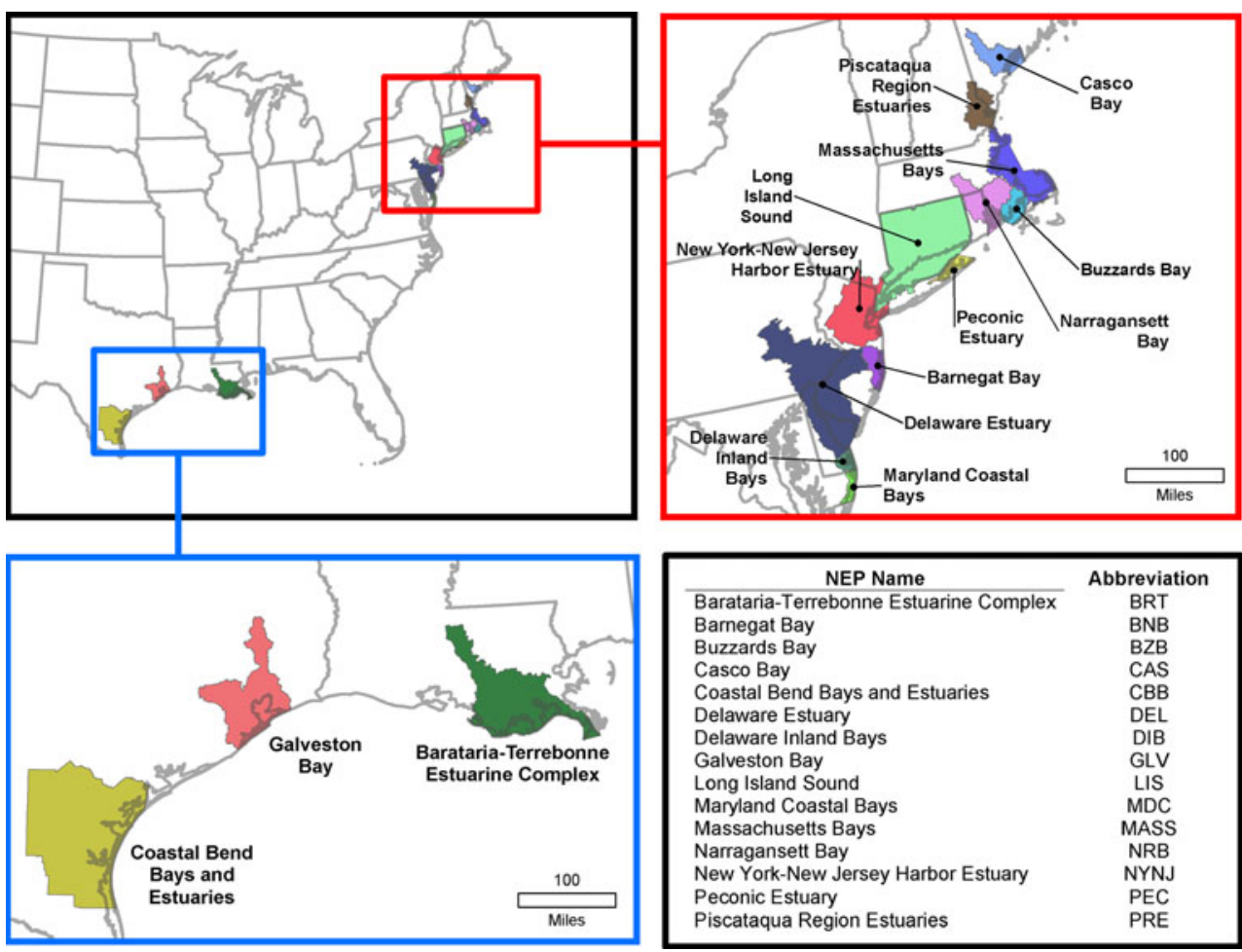

Table 1 Data incorporated into the multi-metric categorical indices estuary condition, land use index, and socioeconomic index, noting the source of data and time period of collection

\begin{tabular}{|c|c|c|}
\hline Data used & Source & Time period \\
\hline \multicolumn{3}{|l|}{ Estuary condition } \\
\hline Water Quality index & NEP Coastal Condition Report & $1997-2003$ \\
\hline \multicolumn{3}{|l|}{ Sediment Quality index } \\
\hline \multicolumn{3}{|l|}{ Benthic index } \\
\hline \multicolumn{3}{|l|}{ Fish Tissue Contaminant index } \\
\hline \multicolumn{3}{|l|}{ Land Use index } \\
\hline$\%$ Human impacted (developed, cultivated, pasture) & CCAP Data (NOAA) & 2006 \\
\hline$\%$ Wetland & & 2006 \\
\hline$\%$ Human impacted: change $96-06$ & & 1996-2006 \\
\hline$\%$ Wetland: change $96-06$ & & 1996-2006 \\
\hline \multicolumn{3}{|l|}{ Socioeconomic index } \\
\hline$\%$ Adults $>25 \mathrm{w} /$ less than high school education & Rand CPHHD SES index & 2000 \\
\hline \multicolumn{3}{|l|}{$\%$ Male unemployment } \\
\hline \multicolumn{3}{|l|}{$\%$ Households w/ income below poverty line } \\
\hline \multicolumn{3}{|l|}{$\%$ Households receiving public assistance } \\
\hline \multicolumn{3}{|l|}{$\%$ Households w/ children headed by female } \\
\hline Median households income & & \\
\hline
\end{tabular}

regions of the U.S. Land use data included: (1) land cover percentages of human impacted land (calculated based on developed land categories, cultivated, and pasture land), and wetlands from 2005-2006 and (2) the sign and magnitude of land cover change of the above mentioned categories from 1996 to 2006. Each land use metric was calculated as a percentage of land cover within the NEP and normalized based on the binning process (Table 1).

A third set of metrics was used to build a socioeconomic index to assess the vulnerability and adaptive capacity of the human systems within each NEP. This index is largely representative of the capacity of the communities within 
the NEP boundaries to adapt to present and future environmental change in order to protect estuary health and water quality. Socioeconomic index data was calculated using Rand Corporation's Center for Population Health and Health Disparities (CPHHD) Data Core index on disadvantage variables. Data were based on the 2000 US Census aggregated at the census tract level and calculated for the NEP boundaries that were provided by the NEP Program at the USEPA. Data from the variables included information on education, unemployment, family structure, poverty, and household income (CPHHD 2007) (Table 1). Such variables have been shown to increase or decrease the vulnerability of social systems and are well supported by the literature (Cutter and others 2003; Education: Heinz Center for Science, Economics, and the Environment, 2000; Unemployment: Mileti 1999; Family Structure: Morrow 1999; Punete 1999; Heinz Center for Science, Economics, and the Environment 2000; Poverty and Income: Hewitt 1997; Puente 1999; Cutter and others 2000).

\section{Index Creation}

Multi-metric indices were created using spatially explicit data and summarizing characteristics by NEP boundaries using ArcGIS 9.3.1 (ESRI 1999-2009). NEP boundaries were delineated by the Office of Wetlands, Oceans, and Watersheds at the USEPA and imported as shapefiles into GIS. Because of potential heterogeneity in data type and collection methodology, a cautionary manner for incorporating data in a composite metric was used to place subjects in groups, rather than using exact measures (Kraay and others 1999). Therefore, for each of the key metrics, the range of data was divided into quintiles, and each estuary was assigned to a quintile. Each estuary was assigned a score of 1-5 for each metric, with a score of 5 representing greater vulnerability and 1 representing less vulnerability. Such an approach enables an average score to be calculated across all metrics to produce a composite index (Brooks and others 2005).

Estuary condition data were scored and averaged using this format within the National Estuary Program Coastal Condition Report, so no further manipulation was required. Socioeconomic data within the Rand SES data set had been previously combined into an index for each census tract; therefore the overall index for each NEP was calculated by averaging the SES score of all census tracts coincident with the NEP. Once an NEP index was obtained for each estuary, the range of data was divided into quintiles to match the scoring system previously presented. Individual metrics for the land use index were calculated using GIS. Data for each metric were then divided into quintiles and averaged for the final composite land use index score.
Data Analysis

Two analysis approaches were used in this assessment. One assessment approach was to average the categorical indices into a final composite score, producing a relative ranking where estuaries with higher composite scores would be considered more vulnerable than those with lower scores. This initial examination of relative ranking was informative in understanding the general order of estuaries based on the selected data and categorical analysis. The relative ranking framework should be seen as a system for comparing estuaries relative to one another, highlighting estuaries that have attributes and potential adaptation plans which may be adopted by lower ranked estuaries to reduce vulnerability.

A second analytical approach was taken in order to increase the ability of the analysis to target specific vulnerabilities. A generic compiled score (relative ranking) does not relay enough information to understand the specific vulnerabilities of each estuary and the types of adaptation that should be developed. Therefore, a secondary step in the analysis may be necessary to "unpack" the compiled score and parse out differences in community types. In this analysis, we divided the vulnerability cube into eight sub-cubes (Fig. 1b), where each of the sub-cubes represent clusters of estuaries with similar vulnerability traits, which we call typologies. These typologies have been determined a priori for this analysis using the subcube system, but other types of clustering and typology development can be accomplished depending on the number of communities within the analysis (please see discussion). Communities in the same typology exhibit similar vulnerability characteristics based on the combined categorical indices within the three-dimensional space of the larger vulnerability cube. Estuaries grouped in the same typology may also potentially have similar adaptation options and be able to develop transferable adaptation options to other like-estuaries.

\section{Results}

The averaged composite scores for each estuary in the relative ranking table (Fig. 3) show the order of relative vulnerability amongst the various estuaries, with higher ranked estuaries experiencing overall less vulnerability to environmental change. Additionally, the estuary rankings have been mapped such that the spatial distribution of estuaries and their vulnerability levels can be seen. Of the 15 NEPs within the analysis, the highest ranked estuary is Peconic Estuary (PEC) in the Northeast with an averaged score of 1.64. PEC exhibited very good estuary condition (1.67) and socioeconomic index (1.0) with medium land 
Fig. 3 Relative rankings table and map of the 15 NEPs included within the analysis. NEPs have been listed in rank order based on an average of the three categorical indices. The color spectrum from green to red indicates estuary systems with the least to most vulnerability

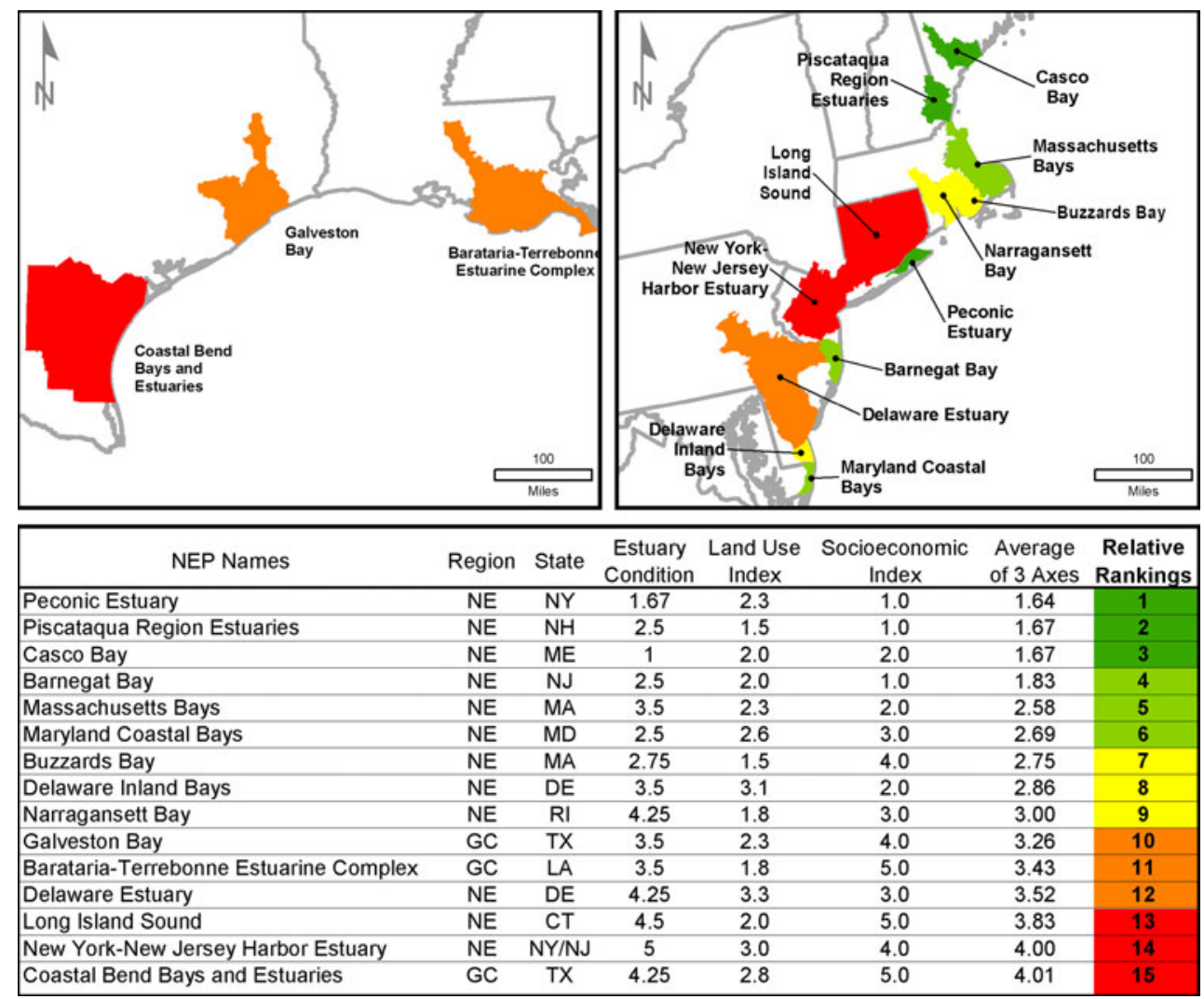

a circle and a triangle. Not all sub-cubes were occupied by more than one estuary, and some were unoccupied. The fifteen estuaries were distributed (from most to least populated) with five NEPs in sub-cube 1; four NEPs in subcube 7, which also contains all three of the Gulf Coast estuaries; two NEPs in sub-cube 3 and 8; and one NEP in sub-cube 4 and 5 . There were no NEPs located in sub-cube 2 and 6.

\section{Discussion}

The results show that the above presented methodology can be an effective, systematic model in which to select and categorize consistent data, aggregate data into compact indices, and visually analyze relative vulnerability across three categories for a number of coastal, estuarine communities. The challenge of assessing vulnerability under environmental change may benefit tremendously from this methodology by easing the complexity and burden of diverse data (Eppler and Mengis 2004). The vulnerability cube methodology also allows the practitioner to access the information at two levels of complexity in the output (the one-dimensional relative ranking score and the three dimensional vulnerability cube), as the two different types of output may be useful for different aspects of decisionmaking. 


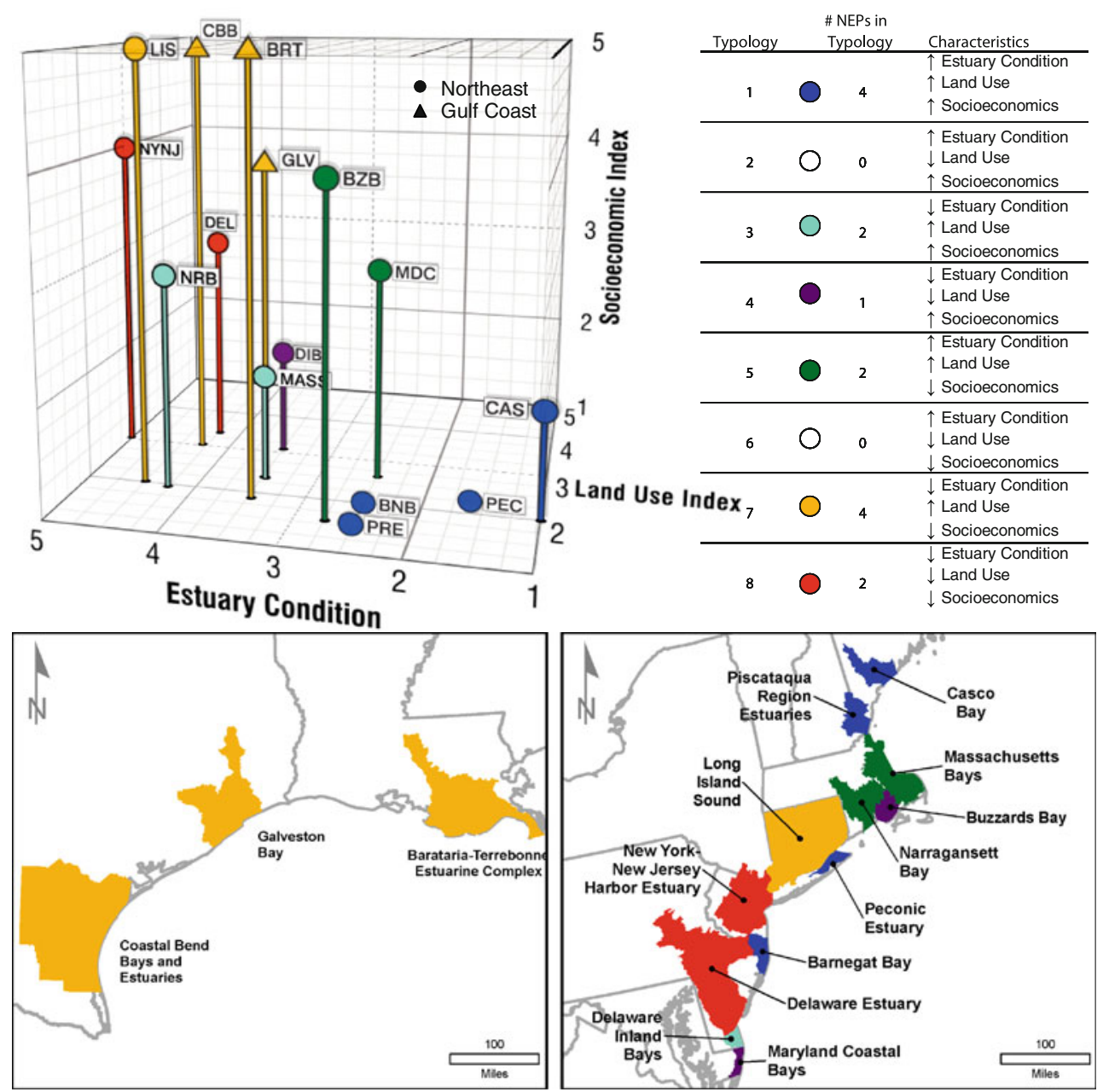

Fig. 4 Vulnerability cube and map of the 15 NEPs broken down into the eight sub-cube typologies. Sub-cubes are distinguished by different colored circles (Northeast estuaries) and triangles (Gulf

The relative ranking portion of this analysis (Fig. 3, far right column) reports the overall vulnerability ranking for each community. This condensed score may be helpful for decision-makers at a federal level, for example, to assess the relative gains of estuaries under restoration/management initiatives or focus funding to the estuaries and/or sectors that are ranked lowest. At the estuary management scale, the relative ranking of estuaries may allow one management group to look toward another higher ranked estuary as a model of a management system with helpful policy options (Fig. 3). Estuaries in the region that are of better rank could act as potential partners for developing and implementing management options that increase estuary health. For example, one estuary management system may have already created a pollution credits system within the watershed to reduce the amount of agricultural nutrients coming into the estuary. This knowledge of creating a useful policy for reducing nutrients from surrounding
Coast estuaries). The number of NEPs located within each sub-cube and the characteristics generally described by the sub-cube is detailed next to the legend

landscapes could reduce the vulnerability score of estuaries suffering from poor land use management.

Care should be taken, however, to avoid the interpretation of "least vulnerable" as "not vulnerable". It is important to reiterate that the estuaries in this example study are only ranked relative to one another, giving the audience an idea of which estuary may be more at risk than others. This does not mean that the estuary receiving the highest score is not vulnerable to environmental change and does not need to receive funding support from a federal agency or has all the policy in place already to prevent estuary health from decreasing. On the contrary: we assume that all estuaries are vulnerable to environmental change, particularly in the face of a changing climate, and use the vulnerability cube approach here as a prioritization tool to help assess and develop policies that can reduce potential vulnerability to future changes and move estuaries incrementally into a better situation. 
The typology analysis identifies clusters of like-estuaries rather than the individual rank of each estuary. The goal of this approach is to group estuaries by similar vulnerability types identified by the typology in order to de-emphasize that certain estuaries are in a better condition than others (Fig. 4). The application of the typology analysis may also be useful for prioritization in decision-making, but its utility is different from that of the relative ranking assessment. The typology analysis can bring more information to the table by telling the decision-maker what the vulnerability profile is of the estuary. The profile allows decision-makers to identify the factors that are affecting the estuary and to isolate the category of greatest vulnerability. For example, a federal program, such as the National Estuary Program, has the ability to provide funding to the estuaries in the program to improve estuary health. However, often the funding is given without specific guidance for how it should be used because there is no synthesized information to describe in which ways the estuary is vulnerable. Many times, an estuary management team may also be unaware of the best way to use the funding to improve estuary quality. In this case, the National Estuary Program could take the results of the analysis to guide their funding allocation to specifically target each estuary's greatest vulnerability category. For the three estuaries clustered in sub-cube 3 , with poor estuary condition, but good land use and socioeconomic indices, funding resources could be prioritized to focus on estuary clean-up measures, increased water monitoring, removal of sediment toxins in order to improve estuary scores along the estuary condition axis. In this way, the typologies would allow for funding to be distributed more specifically with the hopes that improvements could be achieved in the estuary in the most economically efficient way possible.

For a large-scale national program, the assessment can be used as a tool to monitor and track the progress of any estuary through time to better assess if the adaptation options implemented achieved a movement toward a lower vulnerability region of the cube (as in Fig. 1c). This may serve as a validation of the process to see if the use of the typology to determine targeted funding of specific policies actually achieved results of reduced vulnerability based on the original metrics selected. Although we have developed typologies for the estuaries, and the National Program may be able to use the typology information to better target their funding, many of the NEPs have not yet begun the implementation process of adaptation strategies, such that monitoring and tracking of progress is still not possible. Therefore, no validation information for the process is presented in this study. However, the goal is to perform future assessments of the estuaries at periodic stages in order to assess the utility of typologies in guiding funding policy at a national level and to see how estuaries are progressing along the three dimensions. Further validation of the indices, relationships between vulnerability and adaptive capacity, and the sensitivity of the assessment to different sets of weighting will be explored in the future using expert judgment data collected through a focus group exercise previously performed by Brooks and others (2005).

At the estuary management scale, the typology system may be able to assist decision-makers in policy management by directing managers toward other exemplar typology groups and the management and policy options that have been successfully implemented. Such management and policy options have the potential to be transferred to other estuaries. For example, estuaries in sub-cube 6 have a high vulnerability ranking along the socioeconomic and land use index. Therefore, the estuaries in sub-cube 6 may look to estuaries in sub-cube 2 (along the socioeconomic axis) for management options that reduce vulnerability within the socioeconomic context (i.e., policy tools that increase funding to education or increase different types of public assistance). They may also look toward estuaries in sub-cube 1 and 5 (along the land use index) for suggestions on ways to improve land use (i.e., wetland restoration projects, tax benefits for building semi-pervious parking lots). The ability to transfer successful and useful management options across estuaries will lead to more efficient development of policies and actions that protect and conserve estuary health. Whether the transfer of management options is from one estuary to another estuary within a typology or across typologies, the transfer and testing of management strategies across this network of estuaries will allow for more efficient development and implementation of management options that reduce vulnerability. The process of validation for this hypothesis is still being assessed, as the transferring and testing of management options is a long process, but we expect it will be useful as an evaluation tool to assess the effect of various management options implemented. Subsequent assessments of the estuaries will have to be performed in order to understand the full utility of typologies in local management and policy transfer within the network.

An additional potential advantage of this model of analysis is that other estuaries not included within the current analysis can aggregate their own data for each index and determine which typology they fall under. This would allow estuaries to evaluate their own estuary, socioeconomic, and land use condition in order to determine management priorities and to find management solutions from other estuaries. This system of evaluation gives managers the ability to conduct their own comparative analyses to other known sample communities and allows a greater range of stakeholders to interact to find adaptation strategies that are successful for specific types of vulnerabilities to environmental change. 
Closer examination of the individual sub-cubes allows one to see the differences of estuaries within a typology as well. Sub-cube 8 represents poor estuary, land use, and socioeconomic condition. Of the two estuaries located in this sub-cube, NYNJ has a lower score in estuary condition than DEL, suggesting that management policies for NYNJ may require a greater focus on improving estuary condition. DEL has a lower score in land use index, suggesting that management policies may require more focus on land use management and land use change.

No estuaries were found in sub-cube 2 or sub-cube 6 . Sub-cube 2 represents estuaries with good estuary condition and socioeconomic indices, but poor land use. Subcube 6 sits right on top of sub-cube 2 with good estuary condition and poor socioeconomic indices and land use. This suggests that these combinations are not very common, and that poor land use indices do not often lead to good estuary condition regardless of the socioeconomic index of the community. However, a greater sample size may be needed to fully understand the implications of this finding.

The a priori typologies, determined as sub-cubes, were useful in this analysis because there were not sufficient data points (communities) to perform other types of cluster analysis. With a greater number of data points, there may be the possibility of determining typology based on the natural clustering patterns that develop amongst the communities in the cube using various spatial analysis techniques such as nearest neighbor/cluster analysis. These other types of clustering techniques may help to determine more precisely where natural typology boundaries are and where in the cube communities tend to cluster (Ananthanarayana and others 2001; Guha and others 2001). The current example also uses data that is placed in quintiles, such that the relative vulnerability is measured, but not the absolute. If vulnerability thresholds could be established for each metric, the power of the analysis would be greatly improved. The difficulty in establishing thresholds for many metrics remains a challenge however, and relying exclusively on metrics with known thresholds may be limiting.

Like other proposed vulnerability assessment frameworks (Malone 2009), we recognize that the vulnerability cube approach proposed in this paper has both strengths and limitations. Critiques of vulnerability indicators have pointed to a lack of transparency in the development and purpose of developing indicators (Hinkel 2011). The strengths of this approach attempt to take into account the critiques and address them within the methodology of the cube framework. These include: the ability to overcome the unit of analysis problem (Eppler and Mengis 2004); the integration of metrics from both socio-economic and environmental perspectives (Eakin and Luers 2006), the use of pre-existing data for transparency and efficiency (an often cited criticism for vulnerability indicators; Hinkel 2011), the visual representation of relative vulnerability to enhance public understanding and engagement in decisionmaking (Simpson and Prusak 1995), and to provide a twostep analysis process which allows for typologies to be developed (Bailey 1994). The strengths of the framework are that it embraces complexity into the assessment while allowing for an easy and transparent communication of the results.

Many of the limitations and caveats, as mentioned in critiques of indicators (Hinkel 2011) are methodological and difficult to resolve. Although data selection for this type of analysis is flexible, the onus of choosing appropriate data in content, availability, and scale is dependent on the practitioner. Data that is available is often not collected at the appropriate scale or is limited in geographic coverage, and many communities may collect similar, but incomparable data. Questions of jurisdictional complexity, scale issues of decision-making to implementation, and influence on vulnerability will often be part of the decision for data selection. These are not small questions that can be easily addressed. On the other hand, the creation of the categorical indices is malleable, thereby allowing the practitioner to adjust the indices based on availability and significance of the data on vulnerability. The categorical index can also be weighted, as certain types of data are deemed to be more significant than others.

Although not implemented in this case-study, metrics may be weighted by those with the appropriate expertise, local knowledge, etc. For example, if cultivated land is weighted as twice as important as the other land uses within the estuary example, than the resulting changes to the land use index may affect the relative rankings and typologies of the estuaries. One common method for providing weighting to data is the process of expert elicitation. This requires a focus group of experts to consider the key data points they find most important for defining and predicting vulnerability, and based on their own expertise in vulnerability assessment to then rank the different indices according to their importance. Thus, the rankings can be used to provide a set of subjectively derived weights to the multi-metric index (Brooks and others 2005).

This assessment framework provides a useful context in which to begin examining the complexity of vulnerability in national or regional assessments of ecosystems and the communities within them. The vulnerability cube provides a system in which data can be combined and collapsed into multi-metric indices, allows for the examination of different categories of vulnerability, and allows for vulnerability categories to be expressed in a visual, highly understandable format within the vulnerability cube. The importance of producing a visual format is to communicate levels as well as types of vulnerability that communities may face. 
The identification of like-communities, or typologies, is an important starting point for a dialogue that identifies transferable management strategies that maximally leverages resources. The ability to track success through time by mapping the community within the cube to specific periods of time after management implementation may also provide a useful methodology to test adaptation strategies and the understanding of vulnerability within the systems. Although this example analysis has focused on constituents of the National Estuary Program, we believe this model of analysis can be applied broadly to a variety of socio-ecological systems with vulnerabilities to large-scale environmental change.

Acknowledgments We are grateful to our colleagues Susan Julius, Britta Bierwagen, Thomas Johnson, Chris Weaver, Amanda Babson, Anne Grambsch, and Michael Slimak in the Office of Research and Development, and to Tristan Peter-Contesse and Jeremy Martinich at the National Estuary Program for their many thoughtful comments while preparing this manuscript. Thank you to three reviewers for their thoughtful comments and suggestions that have significantly improved this article. We would also like to acknowledge the help of Yoojin Lin with the cube graphics in Fig. 4. All financial and in-kind support was provided from the USEPA and AAAS. The views expressed in this article are those of the authors and do not necessarily reflect the views or policies of the U.S. Environmental Protection Agency or the American Association for the Advancement of Science.

Open Access This article is distributed under the terms of the Creative Commons Attribution Noncommercial License which permits any noncommercial use, distribution, and reproduction in any medium, provided the original author(s) and source are credited.

\section{References}

Ackoff RL (1967) Management misinformation systems. Management Science 14:B147-B156

Ananthanarayana VS, Murty MN, Subramanian DK (2001) Efficient clustering of large data sets. Pattern Recognition 34:2561-2563

Bailey R (1994) Typologies and taxonomies: an introduction to classification techniques (Sage University paper series on quantitative applications in the social sciences 07-102). Sage Publications, Thousand Oaks, CA

Bawden D (2001) Information overload, vol 92. British Library Research and Development Department, London

Beck MW, Heck KL, Able KW, Childers DL, Eggleston DB, Gillanders BM, Halpern B, Hays CG, Hoshino K, Minello TJ, Orth RJ, Sheridan PF, Weinstein MP (2001) The identification, conservation, and management of estuarine and marine nurseries for fish and invertebrates. BioScience 51:633-641

Birkmann J (2007) Risk and vulnerability indicators at different scales: applicability, usefulness and policy implications. Environmental Hazards 7:20-31

Brenkert AL, Malone EL (2005) Modeling vulnerability and resilience to climate change: a case study of India and Indian states. Climatic Change 75:57-102

Brooks N, Adger WN (2003) Country level risk measures of climaterelated natural disasters and implications for adaptation to climate change. Tyndall Centre Working Paper 26
Brooks N, Adger WN, Kelly PM (2005) The determinants of vulnerability and adaptive capacity at the national level and the implications for adaptation. Global Environmental Change Part A $15: 151-163$

CPHHD (2007) Neighborhood SES index. RAND Center for Population Health and Health Disparities, Arlington, VA

Cutter SL, Finch C (2008) Temporal and spatial changes in social vulnerability to natural hazards. Proceedings of the National Academy of Science 105:2301-2306

Cutter SL, Mitchell JT, Scott MS (2000) Revealing the vulnerability of people and places: a case study of Georgetown County, South Carolina. Annals of the Association of American Geographers 90:713-737

Cutter SL, Boruff BJ, Shirley WL (2003) Social vulnerability to environmental hazards. Social Science Quarterly 84:242-261

Eakin H, Luers AL (2006) Assessing the vulnerability of socialenvironmental systems. Annual Review of Environment and Resources 31:365-394

Engle VD, Summers JK (1999) Refinement, validation, and application of a benthic condition index for Gulf of Mexico estuaries. Estuaries 22:624-635

Engle VD, Summers JK, Gaston GR (1994) A benthic index of environmental condition of Gulf of Mexico estuaries. Estuaries 17:372-384

Eppler MJ, Mengis J (2004) The concept of information overload-a review of literature from organization science, accounting, marketing, MIS, and related disciplines. The Information Society 20:325-344

ESRI (1999-2009) ArcMap 9.3.1. ESRI Inc

Fraser EDG (2007) Travelling in antique lands: using past famines to develop an adaptability/resilience framework to identify food system vulnerable to climate change. Climatic Change 83: 495-514

Gallopín GC (2006) Linkages between vulnerability, resilience, and adaptive capacity. Global Environmental Change 16:293-303

Glor E (2001) Innovation patterns. The Innovation Journal: The Public Sector Innovation Journal 6:1-39

Good TP, Davies J, Burke BJ, Ruckelshaus MH (2008) Incorporating catastrophic risk assessment into setting conservation goals for threatened Pacific salmon. Ecological Applications 18:246-257

Guha S, Rastogi R, Shim K (2001) Cure: an efficient clustering algorithm for large databases. Information Systems 26:35-58

Halpern BS, Walbridge S, Selkoe KA, Kappel CV, Micheli F, D'Agrosa C, Bruno JF, Casey KS, Ebert C, Fox HE, Fujita R, Heinemann D, Lenihan HS, Madin EMP, Perry MT, Selig ER, Spalding M, Steneck R, Watson R (2008) A global map of human impact on marine ecosystems. Science 319:948-952

Heinz Center for Science, Economics, and the Environment (2000) The hidden costs of coastal hazards: implications for risk assessment and mitigation. Island Press, Covello, CA

Hewitt K (1997) Regions of risk: a geographical introduction to disasters. Longman, Essex

Hinkel J (2011) Indicators of vulnerability and adaptive capacity: towards a clarification of the science policy interface. Global Environmental Change 21:198-208

Hwang MI, Lin JW (1999) Information dimension, information overload and decision quality. Journal of Information Science $25: 213-218$

IPCC (2007) In: Parry ML, Canziani OF, Palutikof JP, van der Linden PJ, Hanson CE (eds) Climate change 2007: impacts, adaptation and vulnerability: contribution of working group II to the fourth assessment report of the intergovernmental panel on climate change. Cambridge University Press, Cambridge and New York, NY

Kraay A, Zoido-Lobaton P, Kaufmann D (1999) Aggregating governance indicators. Research Working Papers, vol 1, pp 1-39 
Luggar K-M, Kraus H (2001) Mastering the human barriers in knowledge management. Journal of Universal Computer Science 7:488-497

Malone EL (2009) Vulnerability and resilience in the face of climate change: current research and needs for population information. Battelle Memorial Institute, PNWD-4087

Meyer JA (1998) Information overload in marketing management. Marketing Intelligence \& Planning 16:200-209

Mileti D (1999) Disasters by design: a reassessment of natural hazards in the United States. Joseph Henry Press, Washington, DC, p 376

Milman A, Short A (2008) Incorporating resilience into sustainability indicators: an example for the urban water sector. Global Environmental Change 18:758-767

Morrow BH (1999) Indentifying and mapping community vulnerabilities. Disasters 23:11-18

NOAA (2009) Coastal change analysis program regional land cover. NOAA, Washington, DC

Norton DJ, Wickham JD, Wade TG, Kunert K, Thomas JV, Zeph P (2009) A method for comparative analysis of recovery potential in impaired waters restoration planning. Environmental Management 44:356-368

O'Brien KL, Leichenko RM, Kelkar U, Venema H, Aandahl G, Tompkins H, Javed A, Bhadwal S, Barg S, Nygaard L, West J (2004) Mapping vulnerability to multiple stressors: climate change and globalization in India. Global Environmental Change 14:303-313

Parkes MW, Morrison KE, Bunch MJ, Hallström LK, Neudoerffer RC, Venema HD, Waltner-Toews D (2010) Towards integrated governance for water, health, and social-ecological systems: the watershed governance prism. Global Environmental Change 20:693-704

Patrick WS, Spencer P, Ormseth O, Cope J, Field J, Kobayashi D, Gedamke T, Cortés E, Bigelow K, Overholtz W, Link J, Lawson $P$ (2009) Use of productivity and susceptibility indices to determine stock vulnerability, with example applications to six U.S. fisheries. U.S. Department of Commerce, NOAA Technical Memo, NMFS-F/SPO-101

Paul JF, Scott KJ, Campbell DE, Gentile JH, Strobel CS, Valente RM, Weisberg SB, Holland AF, Ranasinghe JA (2001) Developing and applying a benthic index of estuarine condition for the Virginian Province. Ecological Indicators 1:83-99

Puente S (1999) Social vulnerability to disaster in Mexico City. In: Mitchell JK (ed) Crucibles of hazard: mega-cities and disasters in transition. United Nations University Press, Tokyo, pp 295-334

Repenning A, Ioannidou A, Ambach J (1998) Learn to communicate and communicate to learn. Journal of Interactive Media in Education, North America, Oct 1998. http://jime.open.ac.uk/ article/1998-7/32. Accessed 27 Jan 2011
Roessig JM, Woodley CM, Cech JJ, Hansen LJ (2004) Effects of global climate change on marine and estuarine fishes and fisheries. Reviews in Fish Biology and Fisheries 14:251-275

Scavia D, Field J, Boesch D, Buddemeier R, Burkett V, Cayan D, Fogarty M, Harwell M, Howarth R, Mason C, Reed D, Royer T, Sallenger A, Titus J (2002) Climate change impacts on U.S. coastal and marine ecosystems. Estuaries and Coasts 25:149-164

Simpson CW, Prusak L (1995) Troubles with information overloadMoving from quantity to quality in information provision. International Journal of Information Management 15:413-425

Smit B, Skinner MW (2002) Adaptation options in agriculture to climate change: a typology. Mitigation and Adaptation Strategies for Global Change 7:85-114

Thrush SF, Halliday J, Hewitt JE, Lohrer AM (2008) The effects of habitat loss, fragmentation, and community homogenization on resilience in estuaries. Ecological Applications 18:12-21

Turner RK, Subak S, Adger WN (1996) Pressures, trends, and impacts in coastal zones: interactions between socioeconomic and natural systems. Environmental Management 20:159-173

USEPA (2000) Guidance for assessing chemical contamination data for use in fish advisories, vol 2: risk assessment and fish consumption limits. U.S. Environmental Protection Agency, Office of Water, Washington, DC EPA-823-B-00-008

USEPA (2007) National Estuary Program coastal condition report. U.S. Environmental Protection Agency, Office of Water, Washington, DC EPA-842-B-06-001

USGCRP (2008) Preliminary review of adaption options for climatesensitive ecosystems and resources (SAP 4.4). U.S. Environmental Protection Agency, Washington, DC

Van Dolah RF, Hyland JL, Holland AF, Rosen JS, Snoots TR (1999) A benthic index of biological integrity for assessing habitat quality in estuaries of the southeastern USA. Marine Environmental Research 48:269-283

Vincent K (2007) Uncertainty in adaptive capacity and the importance of scale. Global Environmental Change 17:12-24

Walling DE (2006) Human impact on land-ocean sediment transfer by the world's rivers. Geomorphology 79:192-216

Weisberg SB, Ranasinghe JA, Dauer DD, Schnaffer LC, Diaz RJ, Frithsen JB (1997) An estuarine benthic index of biotic integrity (B-IBI) for Chesapeake Bay. Estuaries 20:149-158

Worm B, Barbier EB, Beaumont N, Duffy JE, Folke C, Halpern BS, Jackson JBC, Lotze HK, Micheli F, Palumbi SR, Sala E, Selkoe KA, Stachowicz JJ, Watson R (2006) Impacts of biodiversity loss on ocean ecosystem services. Science 314:787-790

Yohe G, Tol RSJ (2002) Indicators for social and economic coping capacity-moving toward a working definition of adaptive capacity. Global Environmental Change 12:25-40 